\title{
AVALIAÇÃO DA QUALIDADE EM USO DE UM SOFTWARE EDUCACIONAL: UM ESTUDO APLICADO AO SENAI/SC
}

\author{
Ademar Perfoll Junior ${ }^{1}$, Nilson Ribeiro Modro ${ }^{2}$ \\ Pós-Graduação em Engenharia de Software - PGES \\ Centro de Educação Superior do Alto Vale do Itajaí - CEAVI \\ Universidade do Estado de Santa Catarina - UDESC \\ e-mail de contato: junior.bsn@gmail.com
}

\begin{abstract}
Resumo
Uma das áreas que fazem parte da engenharia de software é a qualidade de software, que visa estruturar metodologias e padrões para o desenvolvimento de produtos com qualidade. A Organização Internacional de Padronização - ISO (International Standard Organization), através de seus comitês e grupos de discussão, desenvolveram ao longo da evolução dos softwares, alguns padrões e processos para mensurar e determinar o atributo de qualidade em um software, tanto no processo de concepção, até seu uso por parte dos usuários. Porém, as normas ISO não fornecem um padrão exclusivo para a avaliação de softwares educacionais, por este motivo o presente trabalho propõe um processo para avaliar a qualidade em uso de um software educacional, tomando-se por base a Metodologia Senai de Educação Profissional, a ferramenta Scratch, que é o objeto em estudo, as normas NBR ISO/IEC para avaliação de qualidade de software e a metodologia de avaliação TUP (Tecnologia, Usabilidade e Pedagogia) no contexto do SENAI/SC. Este trabalho considerou a seguinte premissa/hipótese: é possível determinar a influência do software educacional no processo de ensino aprendizagem respeitando os critérios de qualidade de software em uso em uma aula de conceitos de programação ou introdução a programação de computadores? Para avaliar esta influência foi utilizada uma pesquisa qualiquantitativa. Os questionários foram disponibilizados para um grupo de alunos do curso de aprendizagem industrial em informática do SENAI de Rio do Sul/SC durante as aulas de conceitos de programação. A pesquisa foi aplicada entre os períodos de março/2015 e abril/2015. Resultados preliminares mostram que o software Scratch é uma ferramenta atrativa e que motiva o aluno para realizar tarefas durante o processo de ensino e aprendizagem. Outro ponto que merece destaque é que o Scratch é uma ótima ferramenta de apoio aos docentes, mostrando deste modo que uma ferramenta educacional bem aplicada cria uma maior integração entre a teoria e a prática, premissa que é indicada e determinada na metodologia de educação profissional do SENAI/SC.
\end{abstract}

Palavras-chave: Educacional.Metodologia. NBR ISO/IEC.Qualidade.Software.SENAI/SC. Scratch. TUP.

\section{QUALITY EVALUATION ON USE OF EDUCATIONAL SOFTWARE: A CASE STUDY APPLIED TO SENAI/SC}

\begin{abstract}
One of the areas that is part of software engineering is the quality of software, which aims to structure methodologies and standards for the development of products with quality. The International Organization for Standardization - ISO, through its committees and groups discussion developed over the evolution of the software, some standards and processes to measure and determine the quality attribute in a software, both in design process, even its use by users. However, the ISO standards do not provide a unique standard for the evaluation of
\end{abstract}


Universidade do Estado de Santa Catarina

Centro de Educação Superior do Alto Vale do Itajaí

educational software, for this reason this paper proposes a process to assess the quality in use of an educational software, taking as basis the SENAI (National Service for Industrial Training) Professional Education Methodology, the tool Scratch, which is the object under study, the standards ISO / IEC for software quality assessment and the assessment methodology TUE (Technology, Usability and Education) in the context of SENAI / SC. This work considered the following premise / hypothesis: Can you determine the influence of educational software in teaching and learning process respecting the software quality criteria in use in a class of programming concepts or introduction to computer programming? To evaluate this influence was used a qualitative-quantitative research. The questionnaires were made available to a group of students of industrial training in computer SENAI of Rio do Sul / SC during class programming concepts. The survey was conducted between the periods March / 2015 to April / 2015. Preliminary results show that the Scratch software is an attractive tool that motivates students to perform tasks during the process of teaching and learning. Another point worth mentioning is that Scratch is a great tool to support teachers, thereby showing that a wellimplemented educational tool allows you to create a better integration between theory and practice, that premise is indicated and determined the methodology professional education of SENAI / SC.

Keywords: Educational. Methodology.NBR ISO/IEC.Quality.Software.SENAI/SC. Scratch.TUP.

\section{Introdução}

O mercado de softwares educacionais têm crescido exponencialmente, principalmente devido as políticas públicas e os investimentos privados que favorecem o crescimento deste segmento. Um exemplo de investimentos no segmento de softwares educacionais é realizado pelo Sistema FIRJAN - Federação das Indústrias do Estado do Rio de Janeiro, que investe desde o ano de 2012 na aplicação de jogos educacionais eletrônicos para o auxílio nas aulas de matemática. Esse projeto se tornou um espelho para outras escolas do Sistema de Federação das Indústrias de outros estados brasileiros. A procura por ferramentas que tornam o processo de ensino aprendizagem mais dinâmico por parte das instituições de ensino, alavancaram este nicho de mercado, um reflexo deste fato são as novas startups de tecnologia educacional que surgiram nos últimos anos, desenvolvendo novos jogos educacionais, simuladores e ferramentas de gestão e apoio educacional. Porém, aliado à maior oferta de softwares há o crescimento também de problemas relacionados a qualidade dos mesmos.

Softwares educacionais, inclusive gratuitos não faltam no mercado, alguns exemplos de aplicações voltadas à educação são o FísicaLab, utilizado para resolução problemas na disciplina de física, o Euklid, utilizado para o desenho de formas geométricas, que pode ser utilizado em disciplinas de matemática, e o GeoEdu, que é um software voltado ao ensino de geografia.

Umas das áreas que fazem parte da engenharia de software é a qualidade de software, que visa estruturar metodologias e padrões para o desenvolvimento de produtos com qualidade. De acordo com Guerra et al. (2009, p.19), pode-se definir qualidade de produto de software como a conformidade a requisitos funcionais e de desempenho declarados explicitamente, padrões de desenvolvimento claramente documentados e as características implícitas que são esperadas de todo software desenvolvido profissionalmente.

Vale destacar que os softwares educacionais, além de exigirem atenção na avaliação de critérios técnicos, ainda envolvem as questões pedagógicas que contemplam a construção do processo de ensino aprendizagem. Segundo Pinto, (2000, p.03), um software educacional possui características que os diferencia dos demais softwares utilizados no trabalho, na medida em que sua ênfase está no aprendizado. 
Universidade do Estado de Santa Catarina

Centro de Educação Superior do Alto Vale do Itajaí

Neste contexto, o presente trabalho tem como objetivo avaliar a qualidade em uso de um software educacional. Tomando-se por base a Metodologia Senai de Educação Profissional, a ferramenta Scratch, as normas NBR ISO/IEC para avaliação de qualidade de software e a metodologia de avaliação TUP (Tecnologia, Usabilidade e Pedagogia), elaborou-se um processo unificado de avaliação aplicado ao contexto do SENAI/SC.

O presente trabalho está estruturado em cinco seções. Na segunda seção, são apresentados os trabalhos correlatos ao tema proposto. $\mathrm{Na}$ terceira seção são apresentadas as metodologias, normas e padrões norteadores da pesquisa, destacando a Metodologia Senai de Educação Profissional, as normas NBR ISO/IEC e Metodologia de avaliação de softwares educacionais denominada TUP (Tecnologia, Usabilidade e Pedagogia). Em seguida, na quarta seção é comentado de forma breve sobre o software educacional que foi objeto de estudo no trabalho e o processo metodológico aplicado ao trabalho, ilustrando e comentando como as normas técnicas, metodologias e padrões de qualidade de software e os dados obtidos contribuíram para a elaboração de um processo unificado de avaliação aplicado ao contexto do SENAI/SC. A seção cinco apresenta uma análise dos dados objetivos. Por fim, são apresentadas as considerações finais do presente trabalho.

\section{Trabalhos correlatos.}

Dentre os trabalhos que abrangem metodologias para avaliação de software educacional encontra-se a proposta de Rezende (2013) que apresenta um modelo de avaliação de qualidade de software educacional para o ensino de ciências. Nesse trabalho, Resende utilizou o modelo TUP como embasamento e, a partir deste modelo e de metodologias pedagógicas foi proposto uma avaliação para aspectos pedagógicos de software e de ensino de ciências, bem como, avaliar questões de tecnologia e usabilidade de softwares educacionais para o apoio no ensino de ciências.

Outro trabalho recente foi o de Nunes et al. (2014), onde apresenta uma proposta para ensino de computação com SCRATCH no ensino fundamental, a partir de um estudo de caso. A pesquisa propõe uma unidade instrucional para o ensino de computação no Ensino Fundamental de forma interdisciplinar, seguindo as diretrizes de currículo para o ensino de computação.

E, relacionado ao tema de utilização de ferramentas educacionais ou modelos de avaliação de qualidade, deve-se ressaltar o trabalho de Pinto (2000). Neste trabalho, por meio de exemplos, são apresentadas algumas técnicas de avaliação que podem ser utilizadas na avaliação de softwares educacionais, bem como, são esclarecidos quais aspectos que devem estar envolvidos nessas avaliações, mostrando os pontos positivos e negativos de cada abordagem.

\section{Normas técnicas e metodologias norteadoras da pesquisa.}

Existem diversas metodologias e padrões utilizados para avaliar softwares educacionais. Esta seção descreve as respectivas normas ISO/IEC, o modelo TUP - Tecnologia, Usabilidade, Pedagogia - e também a metodologia Senai de Educação Profissional - MESP. A partir da compreensão das normas, do modelo TUP e da MESP foi proposta uma abordagem integrada e contextualizada ao estudo de caso detalhado nas próximas seções.

\subsection{Normas ISO/IEC para avaliação da Qualidade.}

A Organização Internacional de Padronização - ISO (International Standard Organization), através de seus comitês e grupos de discussão, desenvolveram ao longo da evolução dos softwares, alguns padrões e processos para mensurar e determinar o atributo de qualidade em um software, tanto no processo de concepção, até seu uso por parte dos usuários. 


\section{REAVI}

Universidade do Estado de Santa Catarina

Centro de Educação Superior do Alto Vale do Itajaí

Esses padrões visam estabelecer o que deve ser avaliado e o que um software deve garantir para o seu desenvolvedor e usuário final, independente do tipo de software e sua aplicação.

Entre as diversas normas disponibilizadas pela ISO, o presente trabalho traz uma abordagem das seguintes normas: NBR ISO/IEC 9126, ISO/IEC 14598 e a ISO 25000. Essa abordagem é descritiva, com intuito de explanar a ligação e cooperação dessas normas durante o processo de avaliação de qualidade de um software em uso. O fato de explanar sobre as normas ISO tem por objetivo demonstrar que elas não norteiam a avaliação de softwares específicos, como por exemplo, os educacionais.

Em 1996, a principal norma que contemplava questões de qualidade para a tecnologia da informação era a NBR 13596 que definia seis características de qualidade e disponibilizava um modelo para realizar o processo de avaliação de qualidade de um software. A NBR 13596 está sendo substituída por duas normas distintas: a NBR ISO/IEC 9126 (Qualidade do produto de software) e a NBR ISO/IEC 14598 (Avaliação de produto de software).

\subsubsection{NBR ISO/IEC 9126 - Qualidade do produto de software.}

A NBR ISO/IEC 9126 define as características de qualidade do produto de software, determinando como podem ser especificados os requisitos funcionais e não-funcionais do cliente e do usuário. Essa norma manteve as mesmas abordagens da NBR 13596 para qualidade de software. De acordo com a ABTN (2003, p. 02), a NBR ISO/IEC 9126 recebeu alguns adendos em relação NBR 13596, no qual destacam-se a inclusão das subcaracterísticas em caráter normativo, baseadas, em sua maioria, no anexo informativo da NBR 13596, que contém as subcaracterísticas de qualidade; especificação de um modelo de qualidade; introdução de qualidade em uso; remoção do processo de avaliação (agora especificado na NBR ISO/IEC 14598); coordenação de seu conteúdo com a NBR ISO/IEC 14598-1. A Figura 1 ilustra a relação entre as Norma NBR ISO/IEC 9126 e NBR ISO/IEC 14598 que substituem a NBR 13596.

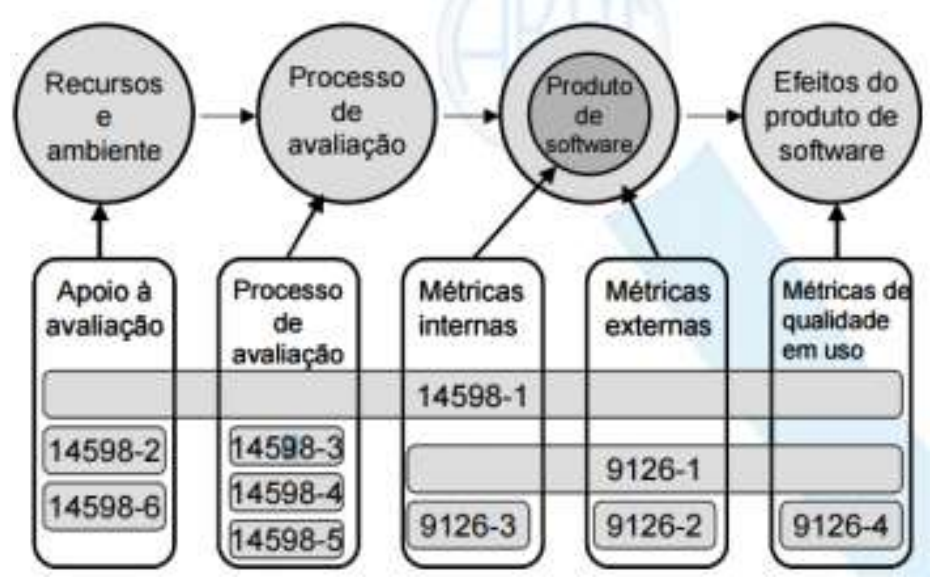

Figura 1 - Relação entre as NBR ISO/IEC 9126 e NBR ISO/IEC 14598. Fonte: ABTN (2003, pág. 02)

Em sua concepção a norma NBR ISO/IEC 9126 foi subdividida em quatro categorias. Cada categoria dessa norma ISO visa avaliar características específicas de qualidade em um software. A primeira parte ou capítulo da norma apresenta apenas definições para as características e conceitos de qualidade de software, como por exemplo, o objetivo da norma, as conformidades, as referências no qual a norma foi estruturada, termos e definições, estrutura do modelo de qualidade, modelo de qualidade para qualidade externa e interna, o modelo de qualidade para qualidade em uso, e por fim, o documento ainda disponibiliza anexos com recomendações para as métricas de qualidade. A segunda parte da norma NBR ISO/IEC 9126, definida pela 
terminologia 9126-2 apresenta as métricas externas para apoiar a definição dos atributos de qualidade de software. Desenvolvedores, avaliadores, gerentes de qualidade e adquirentes podem selecionar as métricas da NBR ISO/IEC 9126-2 para a definição de requisitos, avaliação de produtos de software, medindo aspectos de qualidade e outros fins. Na terceira parte da NBR ISO/IEC 9126, definido por 9126-3 encontram-se as métricas internas de avaliação. Essas métricas consistem em definir critérios para definir indicadores e métricas internas de avaliação de um produto de software. Métricas internas referem-se a medições de um produto de software a partir de suas próprias características internas, sem a necessidade de execução dos programas, que podem envolver quantidade de erros encontrados, linhas de código fonte, entre outros recursos. A quarta e última parte da norma NBR ISO/IEC 9126-4 fornece um modelo de métricas destinadas a avaliação de softwares. Neste documento está contemplada uma explicação de como aplicar as métricas de qualidade de software e um exemplo de como aplicar as métricas durante o ciclo de vida do produto software. Neste modelo também estão inclusos informativos em anexo para colaborar com o processo de utilização da norma.

\subsubsection{NBR ISO/IEC 14598 - Avaliação de produto de software.}

O objetivo da NBR ISO/IEC 14598 é complementar a NBR ISO/IEC 9126, orientando no planejamento e na execução do processo de avaliação da qualidade do produto de software, bem como, permite que a avaliação seja padronizada.

A NBR ISO/IEC 14598 é utilizada em processos de certificação das normas de qualidade, é uma norma que pode ser utilizada por desenvolvedores, adquirentes e empresas que realizam certificações de qualidade de produto de software, isso porque, a NBR ISO/IEC 14598 indica critérios bem detalhados para realizar a avaliação. A norma 14598 está estruturada em seis capítulos ou partes:

- 14598-1: Visão Geral;

- 14598-2: Planejamento e Gerenciamento;

- 14598-3: Guia para Desenvolvedores;

- 14598-4: Guia para Aquisição;

- 14598-5: Guia para Avaliação;

- 14598-6: Módulos de Avaliação;

\subsubsection{ISO/IEC 25000 - SQuaRE - Software Product Quality Requirements and Evaluation.}

O conjunto de normas da cadeia 25000 da ISO é uma evolução das normas 9126 e 14598 , lançada inicialmente em agosto de 2005. Fornece orientação para o uso da nova série de normas internacionais denominadas Requisitos de Qualidade e Avaliação de Produtos de Software (SQuaRE). A Figura 2 ilustra a relação das normas NBR ISO/IEC 9126 e 14598 com a ISO/IEC 25000, é possível notar que a ISO/IEC 25000 agrupou e estruturou de forma modular as duas normas anteriores, tornando o entendimento das normas mais prático. 
Centro de Educação Superior do Alto Vale do Itajaí
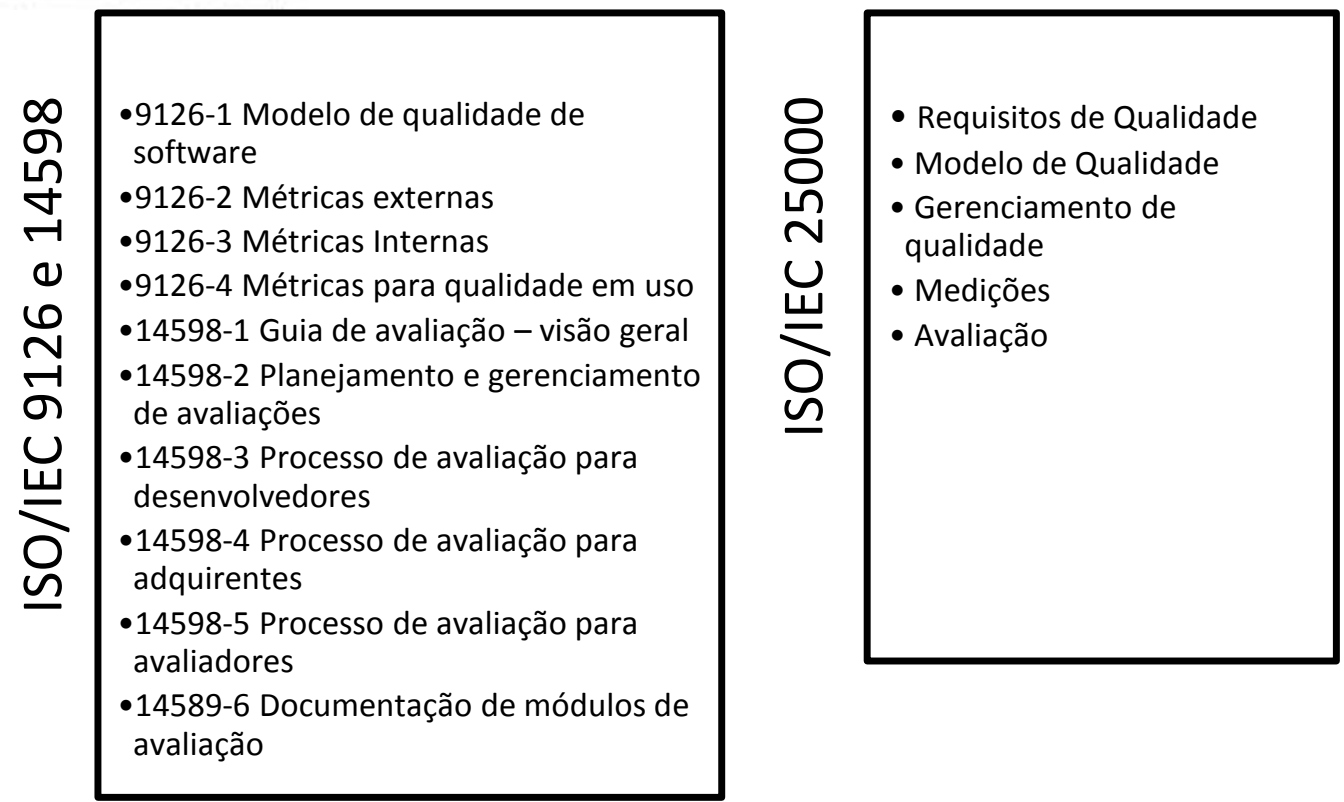

Figura 2 - Relação entre as normas NBR ISO/IEC 9126 e 14598 com a ISO/IEC 25000. Fonte: Acervo do Autor.

Em relação ao comparativo das normas, a norma ISO/IEC 25000 introduziu um novo modelo de referência para aplicar a avaliação de qualidade de um produto de software. A nova norma também traz um detalhamento para cada divisão e elementos de medida de qualidade dentro de cada divisão da norma.

A norma divide os requisitos de qualidade e incorpora uma nova revisão dos processos de avaliação. A ISO/IEC 25000 está em conformidade com a ISO/IEC 15939 que determina os processos de medição.

Porém, dentre as normas ISO/IEC não há nenhuma norma específica para avaliação de qualidade de software educacional. Deste modo, a próxima seção apresenta um modelo que prevê a avaliação desta modalidade de software.

\subsection{Modelo TUP - (Tecnologia, Usabilidade, Pedagogia).}

O modelo TUP, do inglês Technology, Usability and Pedagogy, destaca a importância de se avaliar e selecionar cuidadosamente um software educacional, através de uma abordagem interdisciplinar que compreende aspectos de tecnologia, usabilidade e pedagogia, integrados em um método de avaliação.

Segundo Bednarik (2002,apud Rezende, 2013, p. 21), o motivo do desenvolvimento do modelo TUP foi a necessidade de avaliar adequadamente a intersecção entre a computação e a educação, para a criação de um método de avaliação de software educacional que permitisse aos educadores selecionar softwares de seu interesse, a partir de um conjunto estruturado de critérios. A Figura 3 ilustra a estrutura do modelo TUP, bem como, seus critérios de abordagem: tecnologia, usabilidade e pedagogia. 


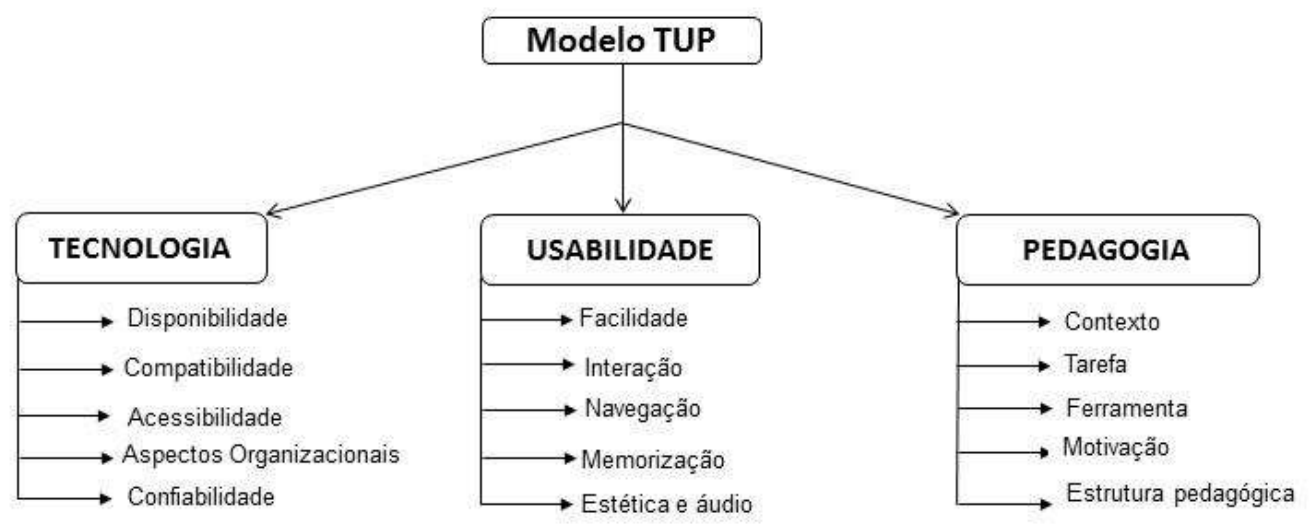

Figura 3 - Modelo TUP adaptado de Bednarik, 2004. Fonte: REZENDE (2013,pág. 22)

De acordo com Rezende (2013, p. 23), o questionário adotado na ferramenta TUP é do tipo checklist e aborda os requisitos e atributos que devem estar presentes no software educacional sob análise, para, a partir daí, se identificar o nível de qualidade do software e as falhas identificadas. Permite também que o usuário faça comentários em formato livre, sobre o software que está sendo avaliado.

\subsubsection{Requisito de Tecnologia.}

No contexto de Tecnologia do modelo TUP de acordo com Rezende (2013, p. 24), estão relacionados aos recursos disponíveis para executar as atividades propostas, ou seja, os critérios e aspectos técnicos, que estão relacionados aos fatores de disponibilidade, compatibilidade, possíveis influências dos equipamentos e sistemas de softwares aos usuários .

Para avaliar os aspectos de tecnologia o TUP conta com um formulário estruturado em vinte e seis perguntas. O Quadro 1 ilustra os atributos de tecnologia avaliados de forma resumida.

Quadro 1 - Atributos referentes ao requisito de Tecnologia do Modelo TUP. Fonte: REZENDE (2013, p. 24)

\begin{tabular}{|l|l|}
\hline \multicolumn{1}{|c|}{ Atributos } & \multicolumn{1}{c|}{ Definições } \\
\hline Disponibilidade & $\begin{array}{l}\text { Refere-se à garantia de que a informação esteja } \\
\text { disponível para uso, durante o maior período de tempo } \\
\text { possível. }\end{array}$ \\
\hline Compatibilidade & $\begin{array}{l}\text { Refere-se a exigências implícitas, relacionadas com o } \\
\text { funcionamento do software em diferentes plataformas } \\
\text { computacionais. }\end{array}$ \\
\hline Acessibilidade & $\begin{array}{l}\text { Refere-se à possibilidade do uso do software por grupos } \\
\text { de usuários com diferentes perfis e necessidades. }\end{array}$ \\
\hline Aspectos Organizacionais & $\begin{array}{l}\text { Refere-se a questões de planejamento, monitoramento e } \\
\text { integração das tarefas apoiadas pelo software, sob a } \\
\text { perspectiva tecnológica. }\end{array}$ \\
\hline Confiabilidade & $\begin{array}{l}\text { Refere-se à garantia de exigências de segurança em } \\
\text { todos os aspectos, estimação e previsão de integridade, } \\
\text { confidencialidade e autenticidade. }\end{array}$ \\
\hline
\end{tabular}

\subsubsection{Requisito de Usabilidade}

No contexto de usabilidade do modelo TUP, são abordados os atributos compreendidos pela interação homem-computador (IHC). Bednarik (2002, apud Rezende, 2013, p. 24), define a usabilidade como a facilidade que os utilizadores possuem quando interagem com um software. 
O modelo TUP utiliza vinte e seis questões para avaliar os critérios de usabilidade em um software educacional. O Quadro 2 ilustra os atributos que são avaliados referentes a usabilidade.

Quadro 2 - Atributos referentes ao requisito de Usabilidade do Modelo TUP. Fonte: REZENDE (2013, p. 25)

\begin{tabular}{|l|l|}
\hline \multicolumn{1}{|c|}{ Atributos } & \multicolumn{1}{c|}{ Definiçães } \\
\hline Facilidade & $\begin{array}{l}\text { Refere-se a quão rapidamente e de forma descomplicada } \\
\text { o usuário consegue explorar o software e realizar suas } \\
\text { tarefas. }\end{array}$ \\
\hline Interação & $\begin{array}{l}\text { Refere-se à maneira pela qual o usuário se relaciona } \\
\text { com o software, entende os comandos e realiza as } \\
\text { tarefas de seu interesse. }\end{array}$ \\
\hline Navegação & $\begin{array}{l}\text { Refere-se aos "caminhos" exigidos para explorar o } \\
\text { sistema, sem alterar o seu estado atual, de acordo com } \\
\text { as exigências específicas para uma tarefa. }\end{array}$ \\
\hline Memorização & $\begin{array}{l}\text { Refere-se a recursos que o software oferece para que o } \\
\text { usuário memorize aspectos de seu funcionamento, } \\
\text { permitindo a utilização por usuários ocasionais ou após } \\
\text { um intervalo de tempo relativamente longo. }\end{array}$ \\
\hline Estética/áudio & $\begin{array}{l}\text { Refere-se a aspectos que imprimem ao software uma } \\
\text { visualização agradável e recursos de áudio adequados, } \\
\text { que deixem o usuário satisfeito. }\end{array}$ \\
\hline
\end{tabular}

\subsubsection{Requisito de Pedagogia}

O critério mais complexo de ser avaliado é o de pedagogia, por envolver diversas questões subjetivas, como o comportamento do usuário e o próprio processo de ensino-aprendizagem. Para incorporar um critério que avaliasse a questão pedagógica, o modelo TUP foi estruturado através de três teorias que tratam dos aspectos do processo de aprendizado do ser humano: a Teoria da Aprendizagem Humana, a Teoria da Aprendizagem Comportamental e a Teoria do Desenvolvimento Cognitivista.

O formulário que trata os aspectos de pedagogia está estruturado com quarenta e duas questões de cunho pedagógico. O Quadro 3 destaca os atributos que compõem o requisito pedagogia.

Quadro 3 - Atributos referentes ao requisito de Pedagogia do Modelo TUP. Fonte: REZENDE (2013, p. 26)

\begin{tabular}{|l|l|}
\hline \multicolumn{1}{|c|}{ Atributos } & \multicolumn{1}{c|}{ Definições } \\
\hline Contexto & $\begin{array}{l}\text { Refere-se aspectos multiculturais e multilíngues, que } \\
\text { devem ser capazes de propiciar uma aquisição de } \\
\text { conhecimento amplo e com diversidade etno-cultural. }\end{array}$ \\
\hline Tarefa & $\begin{array}{l}\text { Refere-se às atividades que compõem o ambiente de } \\
\text { aprendizado, incluindo os meios, ajustes e condições } \\
\text { que conduzem ao alcance do objetivo da aprendizagem. }\end{array}$ \\
\hline Ferramentas & $\begin{array}{l}\text { Refere-se a instrumentos que possibilitam a } \\
\text { compreensão dos processos pedagógicos específicos de } \\
\text { aprendizagem }\end{array}$ \\
\hline Estrutura pedagógica & $\begin{array}{l}\text { Refere-se ao suporte oferecido pelo software para o } \\
\text { gerenciamento de materiais instrucionais, que ofereçam } \\
\text { perspectivas dos estilos e processos de aprendizagem }\end{array}$ \\
\hline Motivação & $\begin{array}{l}\text { Refere-se à capacidade do software de despertar o } \\
\text { interesse intuitivo, de incentivar a conduzir e a cumprir } \\
\text { os objetivos da aprendizagem. }\end{array}$ \\
\hline
\end{tabular}




\subsection{MSEP - Metodologia Senai de Educação Profissional}

A metodologia Senai de Educação Profissional é dividida em três pontos principais, sendo elas as questões que envolvem a definição das características do perfil profissional do discente, as etapas de desenvolvimento de um desenho curricular, e por fim, as práticas docentes, que consistem em um conjunto de etapas didático-pedagógicas empregadas para desenvolver o processo de ensino-aprendizagem.

O presente trabalho tem por objetivo avaliar a qualidade de um software educacional através da percepção de seus usuários, neste contexto estão incluídos os professores e os alunos. Com isso, destaca-se dentro da metodologia Senai de Educação Profissional, o item que descreve a abordagem das práticas docentes, podendo assim, gerar os artefatos de regras de negócio e critérios de sucesso de um software educacional.

A proposta principal da prática docente, segundo a metodologia Senai de Educação Profissional, é capacitar em todas as competências que são esperadas pelo perfil profissional. A Figura 4 ilustra os princípios que compõem a prática docente dentro da MSEP.

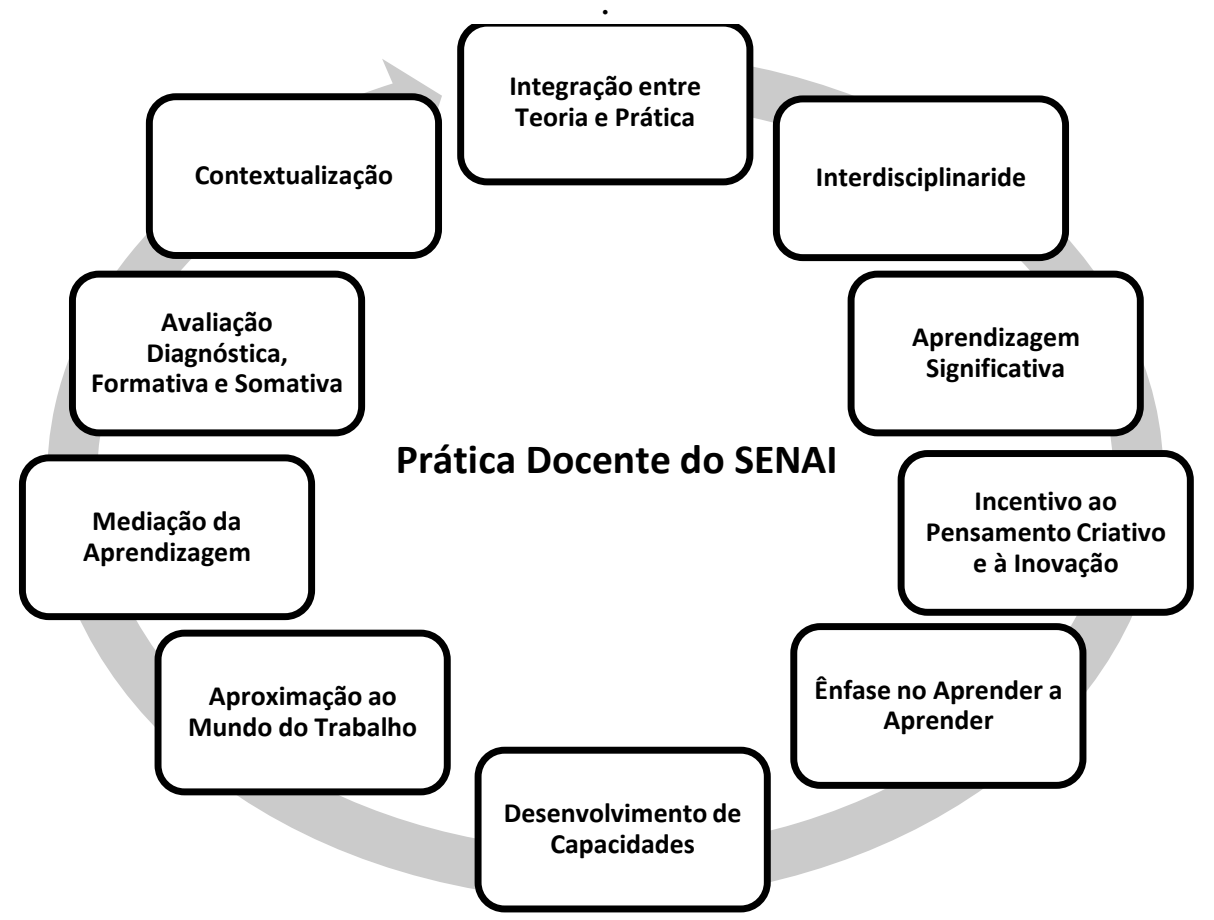

Figura 4 - Princípios norteadores da prática docente do Senai. Fonte: Adaptado de Senai DN

Dentro da estruturação dos princípios norteadores da prática docente do Senai, destacam-se os seguintes itens que podem ser considerados no processo de avaliação de um software educacional:

- Desenvolvimento de capacidades;

- Interdisciplinaridade;

- Ênfase no aprender a aprender;

- Integração entre teoria e prática;

- Incentivo ao pensamento criativo e à inovação;

- Aprendizagem significativa. 


\section{Metodologia.}

O software educacional avaliado é a ferramenta Scratch desenvolvida pelo grupo Lifelong Kindergarten no Media Lab do MIT (Massachusetts Institute of Technology) e está disponível no endereço http://scratch.mit.edu/. Trata-se de uma ferramenta gratuita e indicada para o ensino de programação de computadores. O foco principal da ferramenta é trabalhar questões de lógica, programação e simulação através de uma interface intuitiva e atrativa para os usuários. De acordo com Nunes et al. (2014, p.116), criando programas de software com o SCRATCH, crianças aprendem a pensar criativamente, a trabalhar de forma colaborativa e a pensar de forma sistemática na solução de problemas.Também em relação ao uso do Scratch nas aulas, Oliveira et al. (2014, p.1528) afirma que aprender a lógica de programação se torna mais intuitiva e visualmente mais agradável, pois o próprio ambiente é voltado para computação criativa e design.

Dentro do contexto do Senai, a ferramenta se enquadra em unidades curriculares como conceitos de programação e introdução a programação dos cursos de aprendizagem industrial e técnico em informática para internet.

A avaliação da ferramenta apresentada se deu através da aplicação de uma pesquisa qualitativa e quantitativa com o objetivo de apontar quão o software educacional pode colaborar com o processo de ensino aprendizagem respeitando os critérios de qualidade de software em uso em uma aula de conceitos de programação.

De acordo com as premissas estabelecidas nas metodologias e normas técnicas, é possível determinar os critérios de avaliação, tanto pedagógicos quanto os critérios técnicos esperados pelos usuários da ferramenta. A Figura 5 ilustra os itens abordados na análise das metodologias TUP e MSEP. Neste processo foram elencados os itens que se destacam dentro de cada metodologia e que contribuem para o entendimento da construção do processo de ensino aprendizagem no contexto do SENAI/SC. 


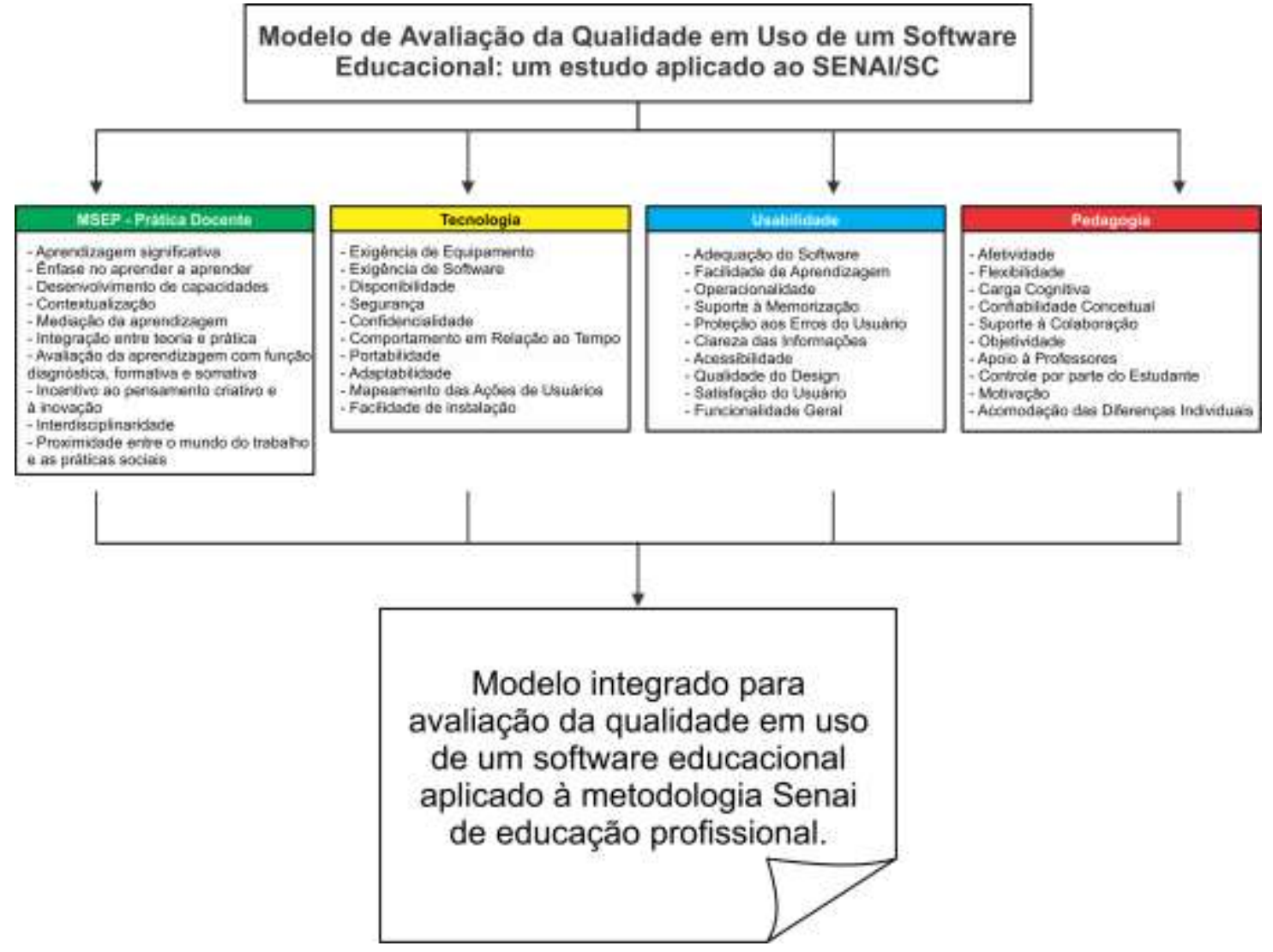

Figura 5 - Processo de elaboração dos critérios de avaliação. Fonte: Acervo do Autor

A Figura 6 ilustra a intersecção entre as metodologias MSEP e TUP, mais precisamente no item Pedagogia. As duas metodologias foram confrontadas para verificar os itens que pudessem gerar redundância no levantamento dos dados. 


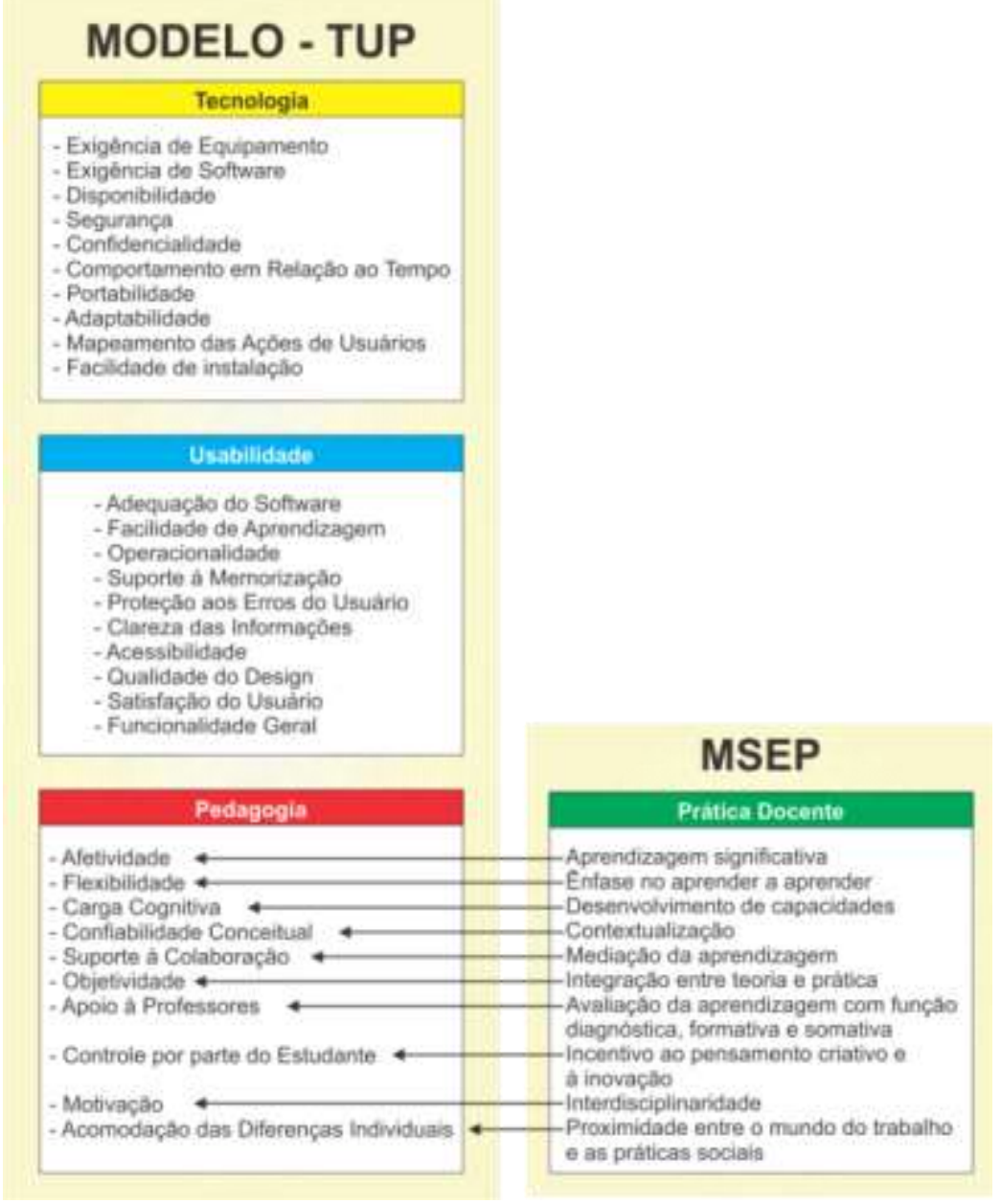

Figura 6 - Intersecção entre a MSEP e TUP - Pedagogia. Fonte: Acervo do Autor

Após a análise comparativa realizada pelo autor e a realização de uma intersecção entre os fatores pedagógicos da MSEP e do modelo TUP, foi realizado um comparativo dos critérios de tecnologia e usabilidade do TUP com as normas NBR ISO/IEC 9126, 14598 e 25000, verificando se o modelo é coerente com padrões nacionais e internacionais de avaliação de qualidade de software em uso.

Para concretizar um modelo de avaliação exclusivo para softwares educacionais no contexto do SENAI/SC foi estruturado um novo processo de avaliação, que pode ser denominado de metodologia integrada. A Figura 7 ilustra o processo de desenvolvimento da metodologia integrada aplicada no trabalho. 


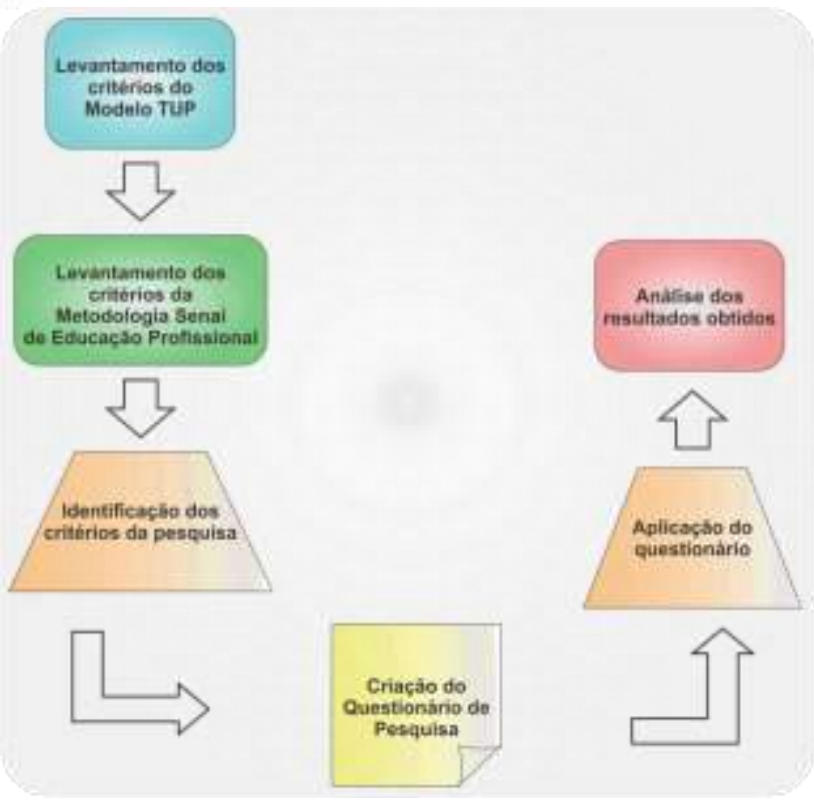

Figura 7 - Processo de aplicação da metodologia integrada. Fonte: Acervo do Autor

O modelo integrado para avaliação foi estruturado em quatro tópicos macros, que agrupam as informações mais relevantes da pesquisa, são eles: aspectos da metodologia Senai de educação profissional (ver Quadro 4), aspectos da metodologia TUP - Pedagogia (ver Quadro 5), aspectos da metodologia TUP - Usabilidade (ver Quadro 6) e por fim, aspectos da metodologia TUP Tecnologia (ver Quadro 7).

Todos os aspectos foram analisados com notas que variam de um (1) à cinco (5), onde um(1) é o valor mais baixo e cinco (5) é o valor mais alto possível para a avaliação.

Quadro 4 - Questionário de aspectos da MSEP . Fonte: Desenvolvido pelo autor

1. As atividades que você realizou no software foram bem definidas pelo professor? Avalie com uma nota de 1 a 5 .

2. O Professor orientou você durante a execução dos exercícios no software Scratch, que nota você atribui para as intervenções efetuadas pelo Professor para ajudar você durante a execução dos exercícios? Dê uma nota de 1 a 5 .

3. As atividades que o professor propôs para realizar no software são compatíveis com os conteúdos teóricos repassados por ele nas aulas expositivas? Avalie com uma nota de 1 a 5 .

4. O objetivo do professor é favorecer o desenvolvimento das suas capacidades, permitindo você planejar, tomar decisões e realizar com autonomia as atividades ou funções propostas no software. Que nota você atribui para a sua capacidade de resolver os problemas propostos no Software Scratch?

5. Em uma escala de 1 a 5 como você avalia a contribuição do software Scratch para aproximar você com as atividades de programação e lógica exigidas pelo mercado de trabalho?

6. O software Scratch incentiva você a usar o pensamento criativo e a criar soluções inovadoras para os exercícios propostas? Que nota você atribui de 1 a 5 para este item?

7. Em uma escala de 1 a 5 como você avalia a ligação da utilização do software Scratch as disciplinas que envolvem a programação de computadores.

8. Em uma escala de 1 a 5 como você avalia o seu desempenho, o software contribuiu para o seu aprendizado?

9. Em uma escala de 1 a 5, informe qual foi o nível da convivência, de empatia, do bem-estar, da solidariedade, da alegria e do otimismo que a turma obteve durante a execução das atividades na ferramenta Scratch.

10. Em uma escala de 1 a 5, como você avalia o seu interesse em aprender uma outra ferramenta como o Scratch?

Quadro 5 - Questionário dos aspectos de pedagogia no modelo TUP . Fonte: Desenvolvido pelo autor.

1. Na sua avaliação o software Scratch possui rotinas bem definidas para construir com a execução das tarefas solicitadas pelo Professor? Avalie de 1 a 5 . 


\section{REAVI}

Universidade do Estado de Santa Catarina

Centro de Educação Superior do Alto Vale do Itajaí

2. Que nota você atribui a forma como o software lhe proporcionou o controle dos módulos e das ferramentas? Avalie de 1 a 5 .

3. Que nota você atribui ao software Scratch em relação a motivação que ele proporcionou na execução das tarefas? Avalie de 1 a 5 .

4. O software Scratch facilitou a sua aprendizagem? Avalie de 1 a 5.

5. Em uma escala de 1 a 5, como você avalia o uso do seu raciocínio lógico durante a execução das atividades?

6. Como você avalia em uma escola de 1 a 5 o seu envolvimento em relação a utilização do software?

7. Como você avalia a sua auto-aprendizagem utilizando a ferramenta Scratch em uma escala de 1 a 5 ?

8. Avalie em uma escala de 1 a 5, a capacidade do software em despertar em você reações e comportamentos que expressam a confiança nos seus conteúdos e resultados por ele(software) propiciados.

9. Em uma escala de 1 a 5, como você considera a diferença em termos de atitudes, conhecimentos e experiências anteriores entre os alunos que utilizaram a ferramenta Scratch?

10. Em uma escala de 1 a 5, avalie como a ferramenta Scratch contribui para a colaboração e compartilhamento de conhecimentos com outros colegas da classe.

Quadro 6 - Questionário dos aspectos de usabilidade no modelo TUP . Fonte: Desenvolvido pelo autor.

1. Na sua opinião o software Scratch é apropriado para realizar as tarefas solicitadas pelo Professor? Que nota você atribui de 1 a 5 ?

2. O software Scratch é de fácil utilização? Que nota você atribui de 1 a 5 ?

3. Qual a sua opinião sobre a facilidade oferecida pelo software para que o você aprenda a explorar e utilizar os diferentes funcionalidades e realizar diferentes atividades? Que nota você atribui de 1 a 5 ?

4. O software Scratch possui uma interface de fácil memorização dos caminhos e procedimentos de interação para um posterior uso? Que nota você atribui de 1 a 5 ?

5. O software Scratch conseguiu contornar os possíveis erros que ocorreram durante a execução do programa? Que nota você atribui de 1 a 5 ?

6. As informações de conteúdos são apresentadas de maneira entendível no programa? Que nota você atribui de 1 a 5 ?

7. Que nota você atribui de 1 a 5 para a aparência e disposição dos elementos nas telas do software, incluindo texto, ícones, gráficos, cores, etc.

8. Qual a sua satisfação com o software Scratch? Que nota você atribui de 1 a 5 ?

9. Em relação às funcionalidades gerais do software Scratch, que nota você atribui de 1 a 5 ?

10. Avalie de 1 a 5 a capacidade do software de ser usado por pessoas com diferentes perfis e características durante as aulas.

Quadro 7 - Questionário dos aspectos de tecnologia no modelo TUP . Fonte: Desenvolvido pelo autor.

1. Que nota você atribui de 1 a 5 para a capacidade que o software possui de estar disponível em qualquer instante de tempo, quando foi necessário ou requisitado sua utilização?

2. Que nota você atribui de 1 a 5 para os mecanismos incorporados pelo software, capazes de garantir a privacidade do usuário, quanto a sua identificação, mesmo compartilhando e publicando informações?

3. Que nota você atribui de 1 a 5 para a capacidade do software de garantir que os seus dados estarão acessíveis somente aos usuários que possuem autorização de acesso?

4. Que nota você atribui de 1 a 5 para a capacidade que o software tem de atender as condições pré-estabelecidas em relação ao tempo de resposta, processamento e taxa de transferência apropriada?

5. Que nota você atribui de 1 a 5 para a capacidade que o software apresenta para se adaptar a diferentes ambientes (sistemas operacionais), previamente especificados, sem a necessidade de mudanças em outras aplicações?

6. Que nota você atribui de 1 a 5 para a capacidade que o software tem para receber modificações e atender diferentes perfis de usuários?

7. Que nota você atribui de 1 a 5 para a capacidade do software em rastrear e representar para você os caminhos que foram percorridos ao usar o software?

8. Que nota você atribui de 1 a 5 para as facilidades encontradas ao instalar o software em um ambiente préestabelecido?

9. Referindo-se aos equipamentos computacionais (computador, rede, dispositivos específicos) utilizados na execução do software. Que nota você atribui de 1 a 5 ?

10. Referindo-se aos softwares e versões (sistema operacional, linguagens, etc.) utilizados na execução do software. Que nota você atribui de 1 a 5 ? 
Universidade do Estado de Santa Catarina

Centro de Educação Superior do Alto Vale do Itajaí

Os questionários foram disponibilizados para um grupo de 26 alunos do curso de aprendizagem industrial em informática do SENAI de Rio do Sul/SC durante as aulas de conceitos de programação. A pesquisa foi aplicada entre os períodos de março/2015 e abril/2015.

\section{Análise dos resultados.}

A pesquisa foi realizada entre os meses de março e abril de 2015, e todos os 26respondentes participaram de forma voluntária da pesquisa. Para a apresentação e discussão dos resultados, optou-se por considerar os pontos fortes e fracos agrupados por sua característica avaliada, como por exemplo, a metodologia SENAI de educação profissional e o modelo TUP.

A faixa etária dos 26 alunos respondentes corresponde a 53,8\% com idade entre 13 e 15 anos, $34,6 \%$ entre 16 e 17 anos, 7,7\% entre 18 e 19 e acima de 19 anos apenas 3,8\%.

Os pontos fortes foram elencados considerando as abordagens que atingiram maiores percentuais no item 5 (Alta) e os pontos fracos são indicados pelos aspectos considerados importantes que não atingiram a maior nota.

O Gráfico 1 ilustra a compilação das informações referentes aos aspectos da MSEP, informando quais abordagens dentro da metodologia atingiram os percentuais mais altos. Nesta abordagem, o maior destaque dá-se pela Contextualização, que atingiu 62\%. Este item aponta que as atividades propostas pelo docente aplicadas com apoio do software em estudo, favorecem o desenvolvimento das capacidades do aluno de solucionar problemas porque estão vinculadas aos conhecimentos esperados pela unidade curricular. Outra abordagem que obteve destaque, com $58 \%$, foi a Ênfase no aprender a aprender. Essa abordagem indica que as atividades realizadas com um software educacional adequado motivam o aluno a querer saber mais e melhor referente ao conteúdo em estudo. Também com 58\%, a Mediação da Aprendizagem se destacou na pesquisa. Esse índice aponta que o docente pode realizar intervenções intencionais durante a execução dos exercícios por parte do aluno no software, auxiliando o mesmo a desenvolver as capacidades técnicas, ou seja, o docente pode auxiliar o aluno na construção dos exercícios dentro do software educacional.Com 54\% de apontamento na pesquisa, a Avaliação da aprendizagem com função diagnóstica, formativa e somativa, indica que uma abordagem prática com softwares educacionais contribui para a melhoria contínua do processo de ensino e aprendizagem, visto que anteriormente, nenhum outro docente havia utilizado a ferramenta em estudo neste trabalho nas aulas de introdução a programação ou conceitos de programação no Senai em Rio do Sul. Outro índice com 54\%, é a Integração Teoria e Prática, fator fundamental para tornar atrativo o processo de ensino e aprendizagem para os alunos, e considerado muito importante pela instituição SENAI, dentro de sua metodologia de ensino. Essa abordagem é importante para o aluno aplicar os conhecimentos na prática profissional diária. A Aprendizagem Significativa, também obteve 54\%. Essa abordagem indica que o software é adequado para apoiar o aluno no processo de desenvolvimento das competências esperadas pela unidade curricular no qual está inserido, ou seja, um software educacional adequado faz com que o objetivo principal da unidade curricular, que é a construção ou melhoria das competências do aluno, seja atingido em grande escala. Por fim, com 50\%, o Incentivo ao pensamento criativo e à inovação, também se destacaram.Esse ponto da MSEP refere-se ao incentivo de gerar novas ideias por parte dos alunos, tornando-os mais criativos e estimulando-os a pensar e se interessar por outras ferramentas e ideias inovadoras que possam contribuir para o processo de ensino e aprendizagem. Esse aspecto teve boa avaliação pela atratividade trazida pelo software Scratch, fazendo despertar no aluno a criatividade para criar jogos ou programas interativos de forma fácil e com baixa curva de aprendizado para a ferramenta. 


\section{MSEP - Abordagens com os maiores índices}

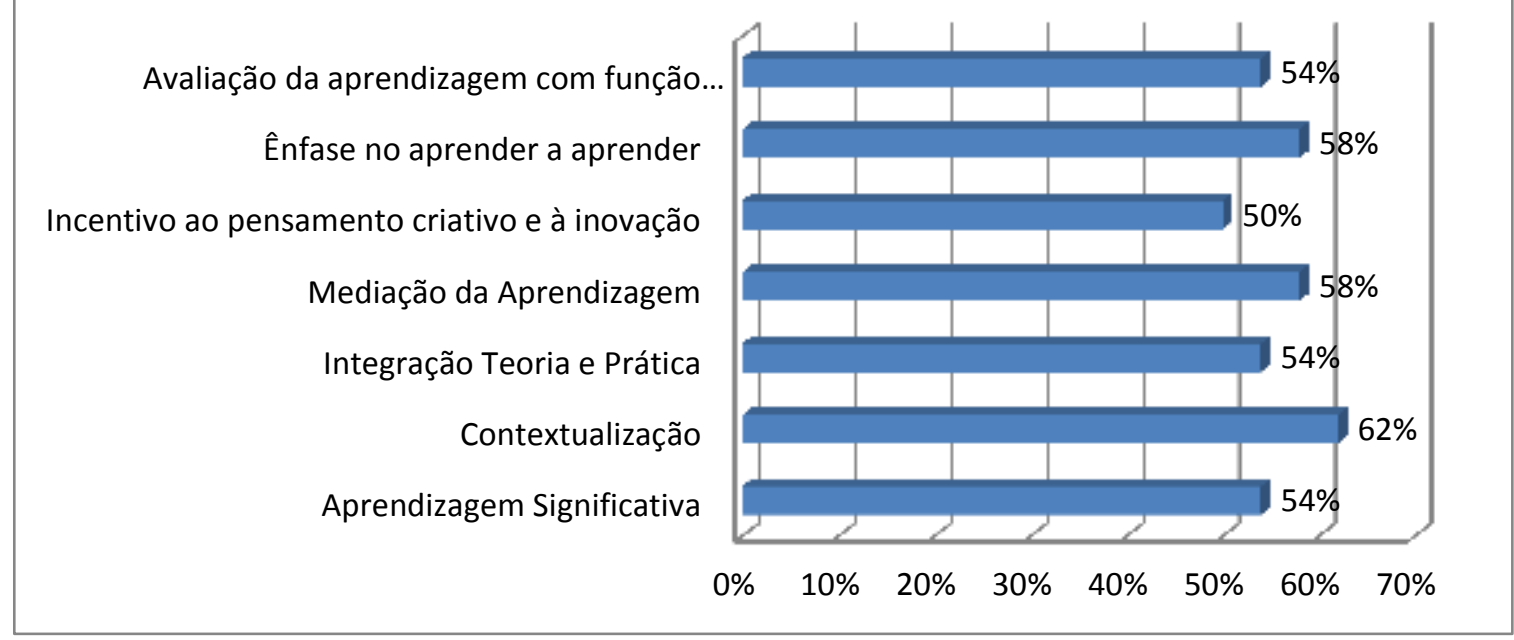

A avaliação mais baixa indicada pelo valor 1(Baixa) não obteve nenhum apontamento na pesquisa da MSEP. Apenas três aspectos da MSEP não atingiram o maior percentual de avaliação na nota 5 (Alta), entre eles o Desenvolvimento de Capacidades com 35\%, A Proximidade entre o mundo do trabalho e as práticas sociais com $46 \%$ e a Interdisciplinaridade com $42 \%$. A justificativa para esses aspectos não atingirem as notas máximas levam em consideração que muitos alunos entre as faixa etárias envolvidas na pesquisa encontram dificuldades para resolver problemas de solução lógica, esse fator impacta na avaliação do Desenvolvimento de Capacidades. Como 54\% dos respondentes ainda não têm idade para trabalhar formalmente,muitos ainda não conhecem a realidade do mercado de trabalho e por isso não visualizam o uso da ferramenta para a descoberta de uma profissão. Por fim, o fator Interdisciplinaridade, pode ter sido dificultado pelo não alinhamento entre os docentes para utilizar atividades que possam ser executadas em softwares educacionais como o Scratch.

Os pontos fortes avaliados que se destacaram nos aspecto pedagógico da metodologia TUP são ilustrados no Gráfico 2. Motivação, Apoio à Professores e Carga cognitiva se destacaram com 58\%. Com a abordagem da pedagogia do TUP para softwares educacionais, é possível identificar a motivação da maioria dos respondentes em utilizar a ferramenta Scratch nas aulas de introdução e conceitos de programação, mostrando que o software é um ótimo recurso para o professor despertar o interesse pela unidade curricular. Também com 58\%, o aspecto de Apoio à Professores indica que a ferramenta Scratch fornece um alto nível de apoio para facilitar a aprendizagem dos alunos. A Carga Cognitiva, outro aspecto avaliado com 58\%, mostra que o software educacional aplicado neste trabalho busca explorar a capacidade de resolução de problemas por parte do aluno, requerendo um esforço mental considerável.Suporte à Colaboração e Objetividade obtiveram 54\% de apontamento na pesquisa entre os aspectos que obtiveram avaliações mais altas. O Suporte à Colaboração indica que a ferramenta educacional Scratch fornece o compartilhamento de conhecimentos e o desenvolvimento de habilidades sociais entre os alunos de uma mesma classe. A Objetividade refere-se à forma de funcionamento do software e dos procedimentos incorporados nele, esse aspecto indica se as tarefas propostas pelo professor podem ser executadas de maneira padronizada no software. 
Gráfico 2 - Abordagens da metodologia TUP-Pedagogia com maiores índices. Fonte: acervo do autor.

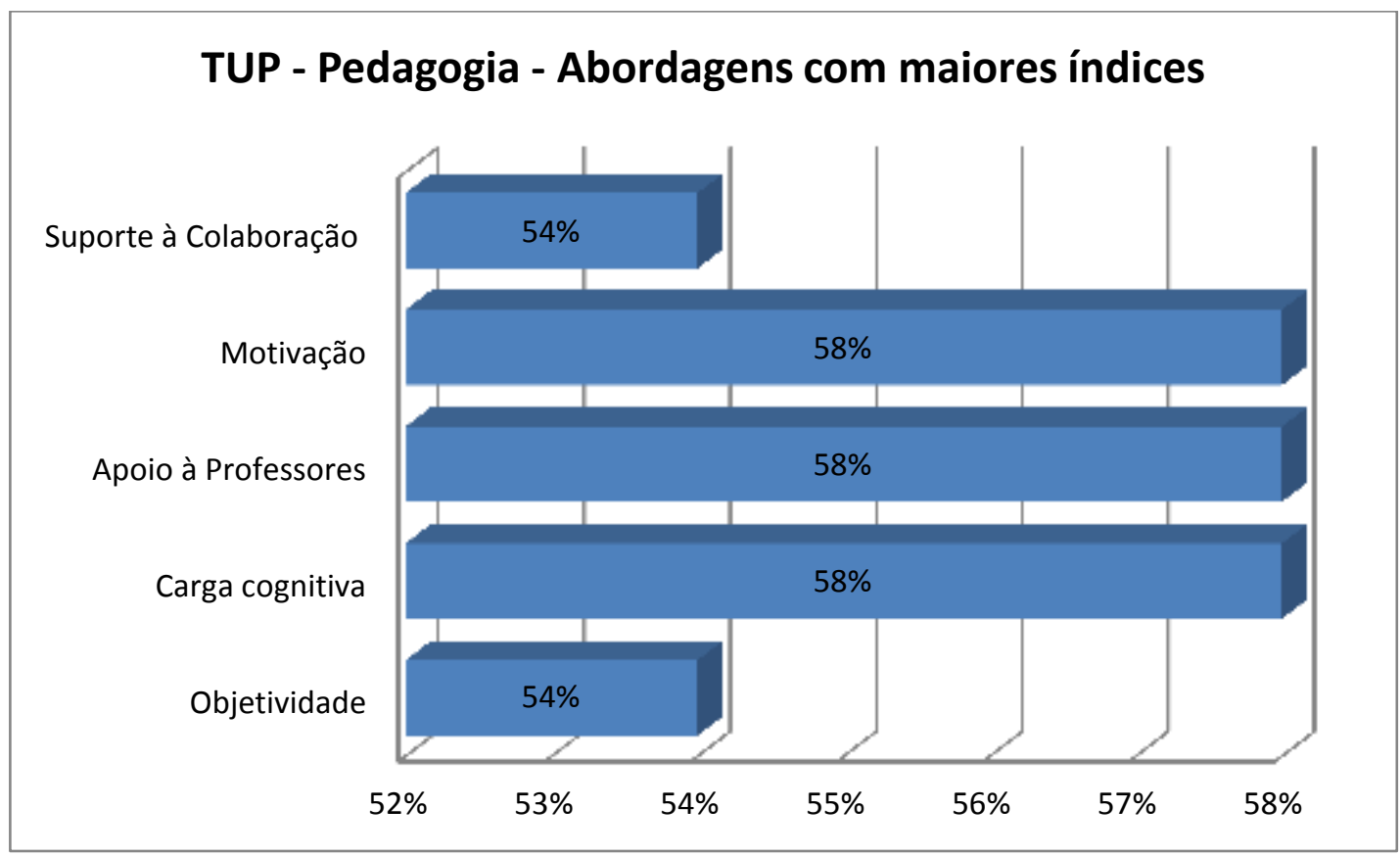

No aspecto pedagógico da metodologia TUP, os pontos que não atingiram as notas máximas foram Afetividade com 35\%, Flexibilidade com $42 \%$, houve $27 \%$ para a Confiabilidade Conceitual e Acomodação das Diferenças Individuai.Por fim,o Controle por parte do Estudante obteve 23\%.O aspecto pedagógico do modelo TUP parece contradizer a MSEP. A Afetividade do TUP-P obteve apenas $35 \%$ de avaliação com nota 5, indicando o envolvimento do usuário e a sua motivação, enquanto na MSEP o aspecto que avalia esse item se mostrou positivo com 54\%. Outro fator contraditório com a MSEP é a Flexibilidade. No TUP-P esse ponto foi avaliado com $42 \%$ de indicação com nota 5 , avaliando a forma como uma ferramenta educacional contribui para o processo de auto-aprendizagem, na MSEP essa característica também se mostrou mais positiva do que no TUP-P, com 58\% de indicação na nota 5. A Confiabilidade Conceitual é um aspecto difícil de ser avaliado, principalmente porque durante a execução das atividades os alunos iniciavam novos projetos várias vezes para testar as várias funções apresentadas pelo programa. $\mathrm{O}$ aspecto de Acomodação das Diferenças Individuais obteve baixa avaliação porque os alunos da classe no qual foi aplicada a pesquisa não obtiveram contato anteriormente com softwares de mesma características do Scratch. O último aspecto que não atingiu a nota mais alta foi o Controle por parte do Estudante conforme mencionado anteriormente.

O Gráfico 3 ilustra os aspectos de Usabilidade do Modelo TUP, os itens que mais se destacaram foram a Adequação do Software, Clareza das Informações, Funcionalidade Geral e Acessibilidade com 54\%.Operacionalidade,Suporte à Memorização, e Qualidade do Design obtiveram $73 \%$, no ponto mais alto da avaliação, enquanto a Satisfação do Usuário obteve 50\% de indicação na nota 5 (Alta). A usabilidade da ferramenta Scratch se mostra bem positiva, principalmente por se tratar de uma ferramenta com curva de aprendizagem baixa. O software se adequou muito bem às atividades de resolução lógica e algoritmos propostas pelo docente. Os alunos também avaliaram com nota máxima a clareza das informações apresentadas no software, a forma de acesso à ferramenta através de vários perfis diferentes de alunos. 
Gráfico 3 - Abordagens da metodologia TUP-Usabilidade com maiores índices. Fonte: acervo do autor.

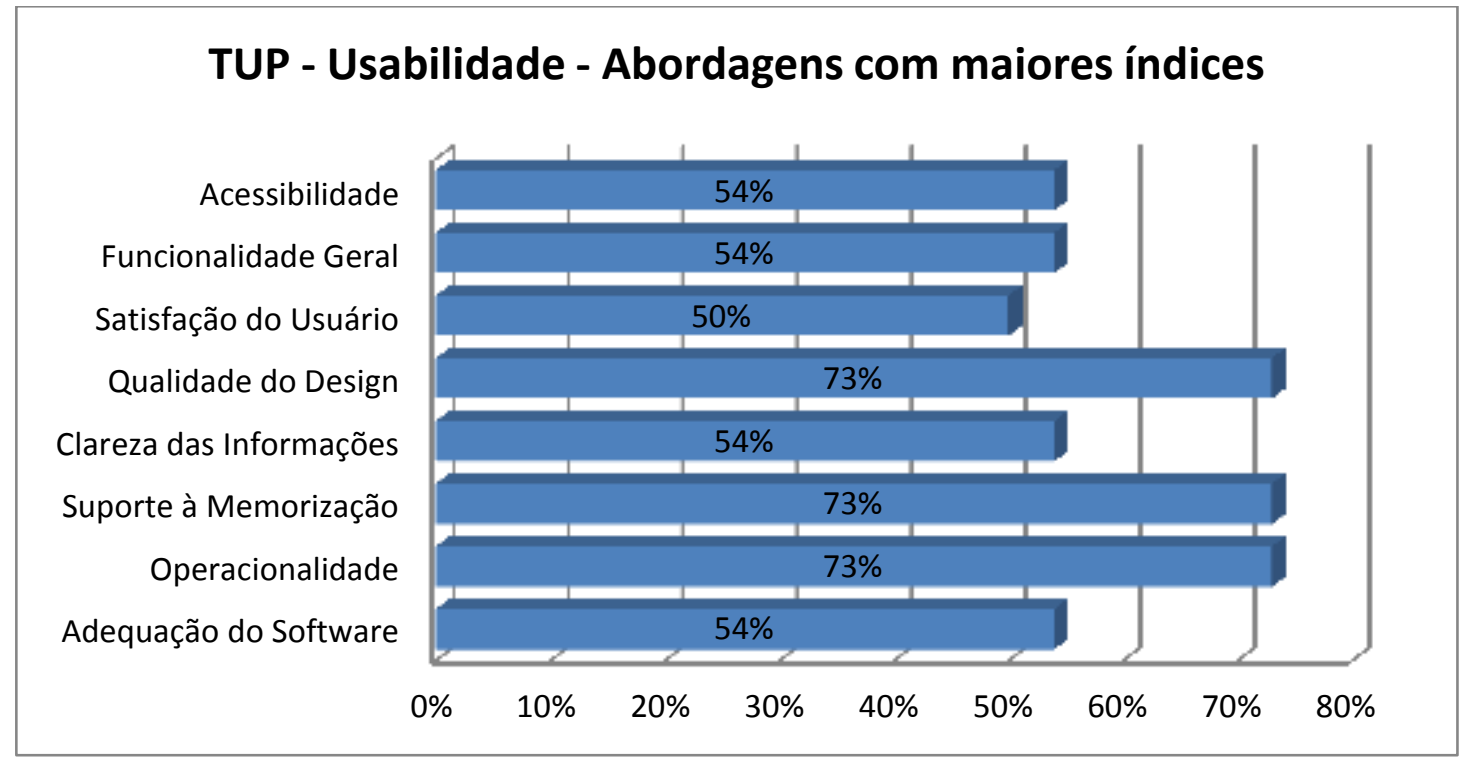

Entre os aspectos que não atingiram a nota máxima de avaliação na usabilidade do TUP estão a Facilidade de Aprendizagem com $42 \%$ e a Proteção aos Erros com $31 \%$ os demais aspectos atingiram ótima avaliação por parte dos estudantes. E a usabilidade é fator fundamental para a utilização da ferramenta, visto que muitos usuários podem não ter experiência com informática. A Facilidade de Aprendizagem não obteve um bom índice porque muitos alunos, durante a execução dos exercícios, estavam preocupados com a finalização dos mesmos e não obtiveram tempo suficiente para explorar outras funcionalidades para tornar a conclusão dos exercícios mais atrativo. A Proteção aos Erros também não pôde ser mensurada de maneira adequada por que o Scratch é uma ferramenta simples e os erros causados durante a utilização podem ser reparados de maneira fácil e simples, principalmente por se tratar de uma ferramenta on-line.

Os aspectos de Tecnologia do Modelo TUP são ilustrados pelo Gráfico 4. Os itens que mais se destacaram foram a Disponibilidade com $73 \%$, Confidencialidade com 58\%, Segurança com 54\%, Adaptabilidade e Exigência do Equipamento que obtiveram 50\% de indicação na nota 5 (Alta) entre os pontos de avaliação. A Disponibilidade foi um fator bem avaliado por questões da ótima infraestrutura de redes de computadores da instituição Senai em Rio do Sul, que dispõe de um link de internet de $30 \mathrm{Mbps}$ para seus usuários. O MIT disponibiliza uma conta para os usuários do Scratch, onde os projetos criados no software podem ser salvos no próprio servidor do MIT, fazendo com que o acesso à informações salvas seja acessível somente para usuários com autorização. Esse fator foi o que impactou positivamente para a boa avaliação da Confidencialidade e da Segurança. A Adaptabilidade também recebeu boa avaliação porque o software não precisou passar por configurações complexas para atender diferentes perfis de alunos.Apenas algumas configurações de resolução e zoom foram necessárias para atender principalmente os alunos com necessidades especiais. Por se tratar de uma ferramenta web, o aplicativo não exigiu grande processamento dos computadores no qual estavam sendo utilizados, impactando positivamente na avaliação da Exigência do Equipamento. 
Gráfico 4 - Abordagens da metodologia TUP-Tecnologia com maiores índices. Fonte: acervo do autor.

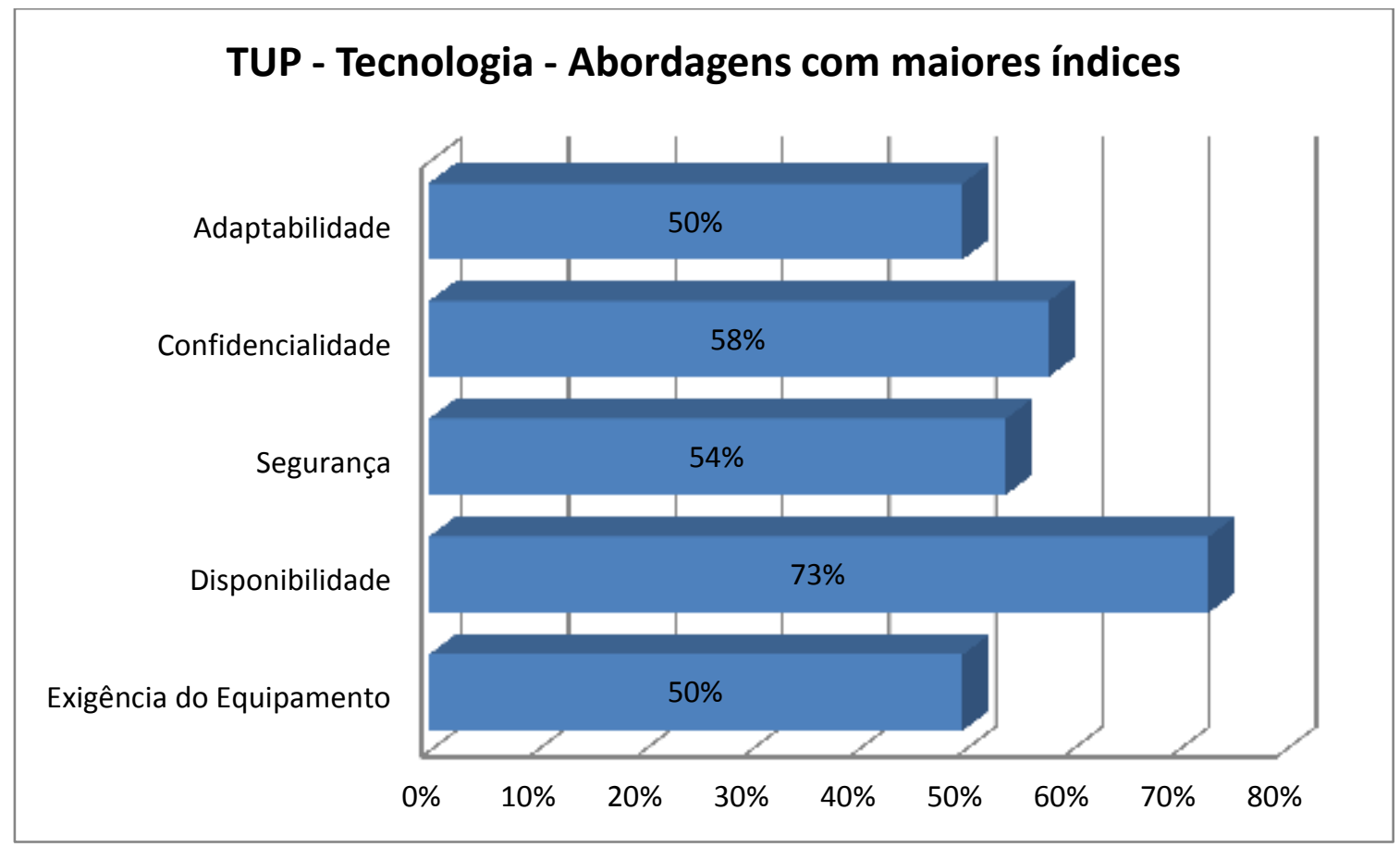

Os pontos fracos indicados nos requisitos de tecnologias do TUP foram Exigência de Software, Comportamento em Relação ao Tempo, Facilidade de instalação.Todos com $42 \%$. A Portabilidade e a Facilidade de instalação ficaram com $42 \%$ de apontamento na nota mais alta de avaliação. $\mathrm{O}$ aspecto da Facilidade de instalação não foi bem avaliado, principalmente pela ferramenta não exigir instalação e esse aspecto não pôde ser avaliado. A Portabilidade não teve a avaliação mais alta porque o software apresentou alguns problemas para executar em navegadores onde o plugin Adobe Flash estava desatualizado, causando descontentamento por parte dos usuários. O Comportamento em Relação ao Tempo não se destacou com a nota de avaliação mais alta porque muitos alunos estavam aprendendo a utilizar a ferramenta e demoravam um tempo considerável para executar os testes dos algoritmos. Por fim, a Exigência de Software ficou aquém de uma ótima avaliação. Isto porque os respondentes não se ateram aos detalhes dos requisitos mínimos de execução do software Scratch.

O Gráfico 5 ilustra a oscilação dos aspectos avaliados em relação a nota 5 (Alta) atribuída à eles. É possível visualizar através do gráfico que mais de $50 \%$ dos aspectos obtiveram avaliação igual ou acima de $50 \%$ de indicação entre as notas disponibilizadas. Isso significa que a classe avaliou muito bem o software Scratch como ferramenta educacional para o contexto das aulas de conceitos e introdução a programação, mostrando ao docente que ele pode continuar os trabalhos com a ferramenta, melhorando as propostas de exercícios e compartilhando com outros colegas da instituição a utilização de softwares educacionais para a construção do processo de ensino e aprendizagem. 
Gráfico 5 - Oscilação de todos os aspectos avaliados em relação a nota 5 (Alta). Fonte: acervo do autor.

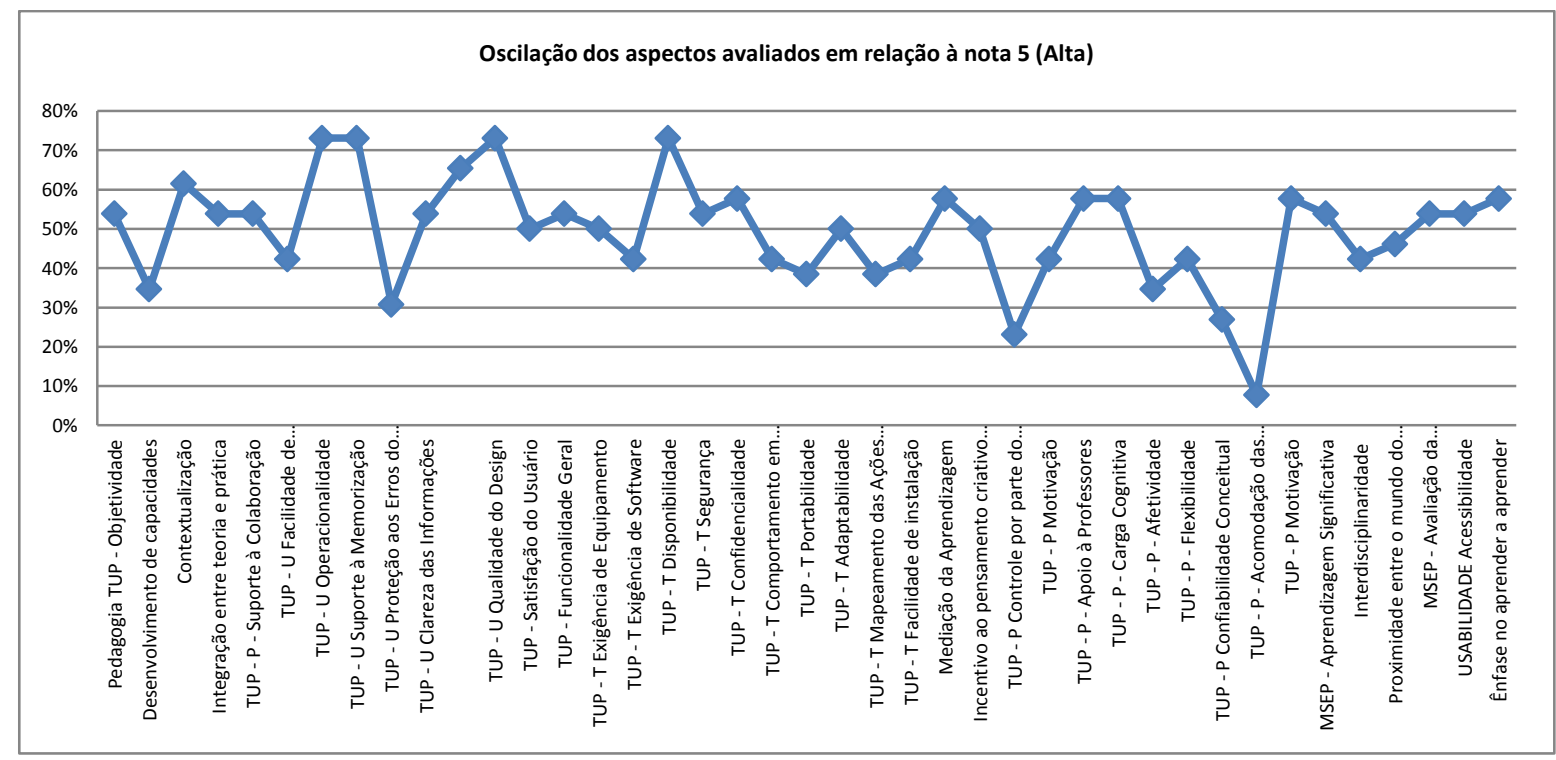

\section{Considerações finais.}

Este trabalho apresentou uma nova proposta para a avaliação da qualidade percebida de softwares educacionais dentro do contexto do SENAI/SC. Esta proposta foi necessária uma vez que somente as normas ISO não possuem a particularidade exigida para a avaliação de softwares educacionais.

Para a criação da proposta aqui apresentada, foi utilizado como referência a metodologia SENAI de Educação Profissional e o modelo TUP proposto por Rezende. As vantagens da utilização de tal proposta são de visualizar a consonância de um software educacional com as boas práticas esperadas pela metodologia educacional do SENAI/SC. Essa proposta de avaliação também permite visualizar o envolvimento dos alunos e quão eles se adéquam às novas práticas docentes. A prática docente exige constante evolução, por exemplo, ou principalmente, para atender os novos perfis de alunos que chegam ao ensino profissionalizante, onde esse é um dos grandes desafios, manter a qualidade no processo de ensino e aprendizagem através de softwares educacionais que auxiliem o docente de forma adequada.

Um ponto bem importante indicado por este trabalho foi a atratividade que um software educacional como o Scratch trás para as aulas de conceitos e introdução a programação, tornando-se uma ótima ferramenta de apoio para os docentes dessas unidades curriculares e confirmando que uma ferramenta educacional pode sim, ser o diferencial na integração da teoria e prática e do processo de ensino-aprendizagem.

É difícil definir a qualidade de um software dentro do segmento de educação por envolver questões de comportamento e aprendizado do ser humano, mas analisando a proposta da MSEP, no que se refere à um trabalho de qualidade por parte dos docentes, o software Scratch se mostrou uma ótima ferramenta. Esse conceito também é concretizado pelo levantamento dos aspectos do TUP, onde é possível visualizar que o Scratch tem uma interface desejável, disponibilidade, recursos para compartilhar o conhecimento e, principalmente, um contexto de fácil entendimento e uma baixa curva de aprendizado.

Para melhorar os critérios que obtiveram grande indicação de notas igual ou abaixo de 3 é notável que não há problemas com critérios técnicos como plataformas e usabilidade, a maior carga de ajustes ficará nos aspectos pedagógicos, como por exemplo, ajustar as atividades 
propostas com os alunos, bem como, a condução das aulas por parte do docente. Esse papel de apoio é executado pela coordenação pedagógica da instituição.

De acordo com as informações coletadas e analisadas é possível identificar que o escopo da pesquisa é muito abrangente. Uma sugestão plausível é fracionar essa pesquisa, como por exemplo, avaliar somente alguns critérios, considerando somente os mais importantes da metodologia SENAI. Aliando à esses critérios o modelo TUP é possível aplicar uma pesquisa em menor abordagem. Com isso será possível analisar e propor a utilização de softwares educacionais em contextos menores.

Em relação às limitações do trabalho, o principal ponto é a falta de uma pesquisa ao término da unidade curricular no semestre ou no ano.Visto que a pesquisa foi aplicada no início do calendário da unidade curricular. Ao final do semestre seria possível traçar um perfil de entrada e um perfil de saída. Com isso, a evolução do aluno quanto ao uso da ferramenta e o aprendizado dos conteúdos ministrados poderiam ser indicados de forma mais eficaz.

\section{Referências.}

ASSOCIAÇÃO BRASILEIRA DE NORMAS TÉCNICAS (2003) "NBR ISO/IEC 9126-1: Engenharia de software - qualidade de produto". Parte 1: modelo de qualidade.

ASSOCIAÇÃO BRASILEIRA DE NORMAS TÉCNICAS (2003) "NBR ISO/IEC 14598-1: Tecnologia de informação - avaliação de produto de software”. Parte 1: visão geral.

BARBOSA, Aline Ferreira; BARREIROS, Emanoel Francisco Spósito; OLIVEIRA, Millena Lauyse Silva de; SOUZA, Anderson Alves de. Ensino de lógica de programação no ensino fundamental utilizando o Scratch: um relato de experiência. In: Congresso da Sociedade Brasileira de Computação, XXXIV, 2014, Brasília: p. 01-1676.

GUERRA, Ana Cervigni; COLOMBO, Regina Maria Thienne. Tecnologia da Informação: qualidade de produto de software. Brasilia: PBQP, 2009. 429p.

NUNES, Vinícius Rodrigues; SANTOS, Giovane Daniel dos; WANGENHEIM, Christiane Gresse Von.Ensino de Computação com SCRATCH no Ensino Fundamental - Um Estudo de Caso. Revista Brasileira de Informática na Educação, São Paulo, v. 22, n. 03, p. 01-126. 2014.

PINTO,Andres D.; CYBIS, W. de A. Um Estudo Teórico sobre as Técnicas de Avaliação de Software Educacional. VI Congreso Argentino de Ciencias de la Computación, 11 p., 2000.

REZENDE,Cristina de Souza.Avaliação de qualidade de software educacional para o ensino de ciências. Itajubá: Universidade Federal de Itajubá, 2013. 134p.

SENAI. Departamento Nacional. Metodologia SENAI de educação profissional. / SENAI. Departamento Nacional. - Brasília: SENAI/DN, 2013. 220 p. 